\title{
LA MENTE HEROICA DE VICO
}

\section{Thora Ilin Bayer (Xavier Univ., Nueva Orleans)}

RESUMEN: La concepción viquiana del ideal sublime de la mente heroica se ha perdido en las doctrinas que rigen hoy la educación contemporánea.

Palabras Clave: G. Vico, $350^{\circ}$ Aniversario, Longinus, prudencia, Dante, Quintiliano, mente heroica, T.I. Bayer.

\section{Vico's Heroic Mind}

ABSTRACT: Vico's vision of the sublime ideal of the heroic mind has been lost in the doctrines that I find governing contemporary education.

KEYworDs: G. Vico, 350"th Anniversary, Longinus, prudence, Dante, Quintilian, heroic mind, T.I. Bayer.

\section{La mente eroica di Vico}

RIASSUNTO: La concezione vichiana dell'ideale sublime della mente eroica si è persa nelle dottrine che, a mio parere, orientano l'educazione contemporanea di oggi.

Parole chiave: G. Vico, $350^{\circ}$ Anniversario, Longinus, prudenza, Dante, Quintiliano, mente eroica, T.I. Bayer.

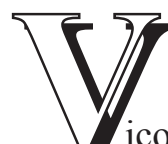
rir el conocimiento humano como un todo: «in summa tamen, qui sapientiae flos esset [el todo es la flor de la sabiduría]». ${ }^{1}$ En De mente heroica (1732), concluido más de tres décadas después, Vico reafirmó dicho principio: «Et quidem certe ab his doctoribus scientiae vobis omnes sunt perdiscendae [No hay doctrina que no hayas de adquirir de tus instructores]». ${ }^{2}$ La concepción viquiana de la sabiduría como una totalidad refleja la definición de Cicerón, según la cual «sapientiam esse rerum divinarum et humanarum scientiam cognitionemque, quae cuiusque rei causa sit [La sabiduría es el conocimiento de las cosas divinas y humanas y la familiaridad con la causa de cada una de ellas]». ${ }^{3}$

Este artículo responde a una invitación expresa por parte de la Dirección de la Revista para este volumen especial por el $350^{\circ}$ Aniversario del nacimiento de G. Vico, habiendo superado los criterios de valoración y del proceso de aceptación. 
Entre los antiguos, sostiene Vico, una única personalidad podría ser considerada como toda una universidad; por el contrario, en el mundo de los modernos, el conocimiento ha tomado la forma de disciplinas particulares. De ahí que la sabiduría requiera atravesar la total enciclopedia de dichas disciplinas, y solo una vez completado este círculo será apropiado para el estudiante especializarse en una materia dada. La concepción viquiana de la educación se enfrenta a la doctrina contemporánea de la interdisciplinariedad, la cual sostiene que los cursos de instrucción han de unificar los distintos campos de conocimiento, y transmitirlos unidos al estudiante. Según esta concepción contemporánea, aunar campos es la responsabilidad de la universidad, no de aquellos que aspiran a ser educados en ella. Dicha teoría contemporánea está basada en la idea de que los campos de conocimiento son divisiones artificiales del pensamiento humano, que habrían de ser superadas, de modo que el estudiante no estuviera expuesto a ellas en absoluto. La gran división entre las cosas divinas y humanas es así ignorada. Al estudiante solo ha de presentársele una corriente de intersecciones entre materias.

En contraste con esta concepción está el reconocimiento, por parte de Vico, de que los campos del conocimiento humano surgen a través de la tradición, y desarrollan de este modo sus propias identidades. El estudiante tiene la responsabilidad de entrar en la forma interior del pensamiento de cada campo y esforzarse por adquirirlo. Además de esta responsabilidad, sostiene Vico, hay una segunda responsabilidad del estudiante, a saber: intentar aunar estas formas individuales de pensamiento en un todo. La sabiduría es adquirida solo cuando uno la asume por sí mismo como tarea. Uno ha de construir esa verdad de la totalidad a través de sus propios esfuerzos; no es algo que pueda ser logrado mediante la instrucción, ni simplemente transferido al estudiante. Los beneficios de este planteamiento son enormes. ${ }^{4}$

Llevar el pensamiento al nivel de la totalidad requiere de una mente heroica. En la edad moderna, la presencia del héroe que lograba ordenar la sociedad y el pensamiento, dominante en la segunda edad de la storia ideal eterna, ha desaparecido. No obstante, dicho héroe permanece, solo que en tanto que ideal. En la tercera edad del corso, Sócrates reemplaza el heroísmo de Aquiles y Ulises. Y el heroísmo socrático no consiste en grandes acciones heroicas, sino en su habilidad para hacer de la virtud un tema del pensamiento. Del mismo modo que Homero es reemplazado en el ricorso por Dante, «el Homero toscano», Sócrates es reemplazado por Vico. Al final de su autobiografía, Vico mismo se pone en relación con

1. En Opere, 2 vols., ed. de Andrea Battistini, Mondadori, Milán, 1990, 1, p. 208. [N.E.- Para esta, así como para las sucesivas citas referidas a las notas número 2,9 y 10, relativas a Sobre la mente heroica y a Del método de estudios de nuestro tiempo, existe traducción crítica española desde el latín: G. Vico, Obras. Oraciones inaugurales \& La antiquísima sabiduría de los italianos, ed. trad. y n. por F.J. NAVARRo GómEZ, Anthropos, Barcelona, 2002.]

2. En Opere, cit., 1, p. 376.

3. Disputaciones Tusculanas, 4.26.57.

4. ThORA Ilin BAYER, Moral Philosophy and Moral Education, Cascade Books, Eugene (Oregón), 2017. 
Sócrates. ${ }^{5} \mathrm{Al}$ igual que hacía Sócrates en sus enseñanzas, Vico aspiró a que fuera la sapienza che parla. La elocuencia, como sostiene Quintiliano, es hablar completamente, poner la sabiduría en un discurso global. ${ }^{6}$ Una universidad es ella misma un discurso global. De ese modo, como sostiene Vico, se puede decir que una universidad es una Sapientia. ${ }^{7}$ Es este discurso global lo que la universidad representa, y a lo que el estudiante debe aspirar. Cuando tal discurso es logrado, se eleva el pensamiento al nivel de lo sublime. ${ }^{8}$

La concepción viquiana de la educación tiene en su base el problema de cómo resolver el contraste entre antiguos y modernos, lo cual era problema de los tiempos de Vico y lo sigue siendo en los nuestros. Los antiguos son expertos en retórica y su atención a la retórica no ha sido efectivamente retomada por los modernos desde que fuera descartada por Descartes. Vico, en su alocución a la Academia de los Oziosi en enero de 1737, bien avanzada ya su carrera, afirma:

«se io non vado errato, porto opinione che [se] ne' nostri tempi l'eloquenza non sia rimessa nel lustro de' latini e de' greci, quando le scienze vi han fatto progressi uguali e forse anche maggiori, egli addivenga perocché le scienze s'insegnano nude affatto d'ogni fregio dell'eloquenza». ${ }^{9}$

Por encima de todo, la mente heroica tiene como objetivo la prudencia. La clave para entender la prudencia es el estudio de la jurisprudencia. La sección de la jurisprudencia, en tanto que campo de estudio, es aquello a lo que apunta el currículum, o método de estudio, según indica Vico en su séptima oración universitaria. Se trata de la parte más extensa de esta obra. Vico conecta firmemente filosofía y ley, sosteniendo que no hay «arte de la jurisprudencia» aparte de la filosofía. Afirma: "Quanquam quid hoc verbi est 'ars prudentiae', cuius una ars est philosophia?» [No hay más que un 'arte de la prudencia', y este arte es la filosofía]. ${ }^{10}$

En el párrafo final de la Pratica, que pretendía ser añadida a la Conclusión de la Scienza nuova (1744) como su segundo capítulo, Vico sostiene este punto con aún mayor fuerza. Lo afirma en la dedicatoria de la Scienza nuova prima (1725): «proponemmo alle università dell'Europa doversi trattare con tutto il complesso dell'umana e divina erudizione, e, 'n conseguenza, ponemmo sopra a tutte le scienze». Además, afirma Vico: «perché i giovani da erudirsi, così disposti, apparino la

5. G. Vico, Vita di Giambattista Vico scritta da se medesimo (1723-1728), en Opere, cit., 1, p. 85.

6. QuintiLIANO, Inst. 8. pr.15-16.

7. G. Vico, De mente heroica, en Opere, cit., 1, p. 378.

8. Ibíd, p. 372.

9. G. Vico, Opere, cit., 1, p. 406; cfr. The Academies and the Relation between Philosophy and Eloquence, trad. ing. de Donald Phillip Verene, en On the Study Methods of Our Time, trad. de Elio Gianturco, Cornell University Press, Ithaca, 1990, p. 87.

10. G. VIco, De nostri, en Opere, cit., 1, p. 158. 
pratica di questa Scienza, fondata su questa legge eterna, c'ha posto la Provvedenza al mondo delle nazioni»..11

La jurisprudencia así concebida es una ciencia maestra que permitirá al estudiante aunar las otras ciencias como una totalidad, la cual es sublime, en el sentido de ser el logro de una síntesis. Como nos muestran las leyes físicas discutidas por Newton y Galileo, la estructura divina del mundo de la naturaleza, así como las leyes del mundo de las naciones -ius naturale, ius gentium, ius civile- nos muestran el orden providencial de la naturaleza humana, así como de la historia humana. La prudencia no es una virtud moral ni un medio para la virtud separado de la ley. Para Vico, la enseñanza de la ley y la teoría de la retórica son una y la misma cosa. La Scienza nuova es ella misma una oración forense que presenta su caso, tanto ante expertos como ante jóvenes lectores. La ley es la encarnación actual de la sabiduría civil. La ley es la fuente de la moralidad, no al revés, y contiene las virtudes encarnadas originalmente en las figuras de los héroes de la era heroica, que acabaron deviniendo costumbres codificadas en el Corpus Juris Civilis romano. La instrucción en este Corpus es una completa sabiduría civil, una guía para la buena conducta del Estado así como del ciudadano en su seno. ${ }^{12}$

Lo sublime es el objetivo de la mente heroica. Aunque Vico no cite a Longinus, podría presuponer que un auditorio bien informado habría de reconocer su pretensión de que lo sublime fuera entendido en el sentido del Peri Hypsos de Longinus. Lo sublime es alcanzado cuando una idea es captada en un único momento. Es un momento de «síntesis» en el que la totalidad de una materia es aprehendida. ${ }^{13}$ Una vez que el estudiante ha experimentado este momento, ha logrado la dimensión heroica de la mente. Y entonces el estudiante puede captar todo el poder retórico del habla, y generar un principio unificador que sea obra del propio estudiante. Es este el sentido de la verdadera educación y su último objetivo. Las doctrinas contemporáneas de la educación generalmente identifican aprendizaje con la adquisición de información. En contra de tales doctrinas está el gran ideal viquiano de la mente heroica y de la educación de la totalidad.

\section{[Traducción del inglés por Jesús Navarro Reyes]

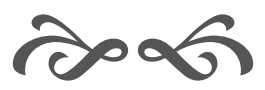

11. G. Vico, La Scienza nuova seconda, 2 vols., ed. de Fausto NicolinI, Laterza, Bari, 1953, 2, pp. 276-277 (§ 1.411); trad. al inglés: The New Science of Giambattista Vico, trad. T.G. BerLin and M.H. Fisch, Cornell U.P., Ithaca, 1984, p. 430 (§ 1.411).

12. Cfr. Thora Ilin Bayer, «Vico's Principle of Sensus Communis and Forensic Eloquence», Chicago-Kent Law Review, 83, 2008, pp. 1.131-1.155.

13. LoNGINUS, Subl. 1.4; 8.1-2. 